\title{
A Role for Complement in the Rejection of Porcine Ventral Mesencephalic Xenografts in a Rat Model of Parkinson's Disease
}

\author{
Roger A. Barker, ${ }^{1}$ Emma Ratcliffe, ${ }^{1}$ Megan Mclaughlin, ${ }^{2}$ Andrew Richards, ${ }^{2}$ and Stephen B. Dunnett ${ }^{1}$ \\ ${ }^{1}$ Cambridge Centre for Brain Repair, Forvie Site, Cambridge CB2 2PY, United Kingdom, and 2/mutran Limited (A Novartis \\ Pharma AG Company), Cambridge CB2 2AH, United Kingdom
}

\begin{abstract}
Vascularized whole organ discordant xenografts placed in the periphery are rejected by a rapid "hyperacute" process that involves preformed antibody binding to the xeno-antigens on the donor endothelial cells with complement activation. In the CNS, xenografts are classically thought to be rejected more slowly by a T-cell-dependent process. We now report that xenografts of embryonic porcine ventral mesencephalic tissue in the 6-hydroxydopamine-lesioned, nonimmunosuppressed rat induce both a humoral and a cell-mediated response. Over the first $10 \mathrm{~d}$ after implantation, the xenografts matured with identifiable TH neurons and pig-specific neurofilament fibers extending along host white matter tracts. During this period of time, IgM and complement binding were observed within the graft, as well as a CD8 cellular infiltrate, leading to rejection of the transplant over the next $25 \mathrm{~d}$. These intracerebral xeno-
\end{abstract}

Allotransplantation of embryonic neural tissue into the diseased CNS has now passed from the experimental stage into clinical trials, at least with respect to Parkinson's disease (PD) and, more recently, Huntington's disease (HD) (Lindvall, 1997; Kopyov et al., 1998). In PD it is now well established that good clinical results can be obtained (Widner, 1998; Fahn et al., 1999), which correlates with fluorodopa uptake on PET scans (Martin and Perlmutter, 1994; Wenning et al., 1997) and dopaminergic cell survival within the grafts in those that have come to postmortem (Kordower et al., 1998). Despite this success, a number of fundamental difficulties remain with the use of fetal human allografts, including ethical and practical limitations on the supply of suitable donor tissues in sufficient quantity. As a consequence, alternative sources of cells have been sought, including the use of embryonic neural tissue from other species, most notably pig.

The use of porcine tissue offers a number of attractions, including the ease of supply and the possibility that xenotransplanted tissue, as opposed to allotransplanted tissue, may have a greater potential for sending axons into the host brain (Wictorin et al., 1992). However, porcine tissue poses potential problems of

\footnotetext{
Received Dec. 2, 1999; revised Feb. 14, 2000; accepted Feb. 16, 2000.

Roger Barker is a Medical Research Council Clinician Scientist. This work was also supported by Imutran Limited (A Novartis Pharma AG Company). We thank Richard Armstrong, Neil Scolding, and Anne Rosser for their critical comments.

Correspondence should be addressed to Roger A. Barker, Cambridge Centre for Brain Repair, Forvie Site, Robinson Way, Cambridge CB2 2PY, UK. E-mail: rab46@cus.cam.ac.uk.

Dr. Dunnett's present address: School of Biosciences, Cardiff University, Museum Avenue, Cardiff CF1 3US, Wales, UK.

Copyright (C) 2000 Society for Neuroscience $\quad 0270-6474 / 00 / 203415-10 \$ 15.00 / 0$
}

grafts were not associated with an early systemic antibody response. A role for complement in this rejection process was further investigated using cobra venom factor (CVF), which systemically depleted the rats of complement for $7 \mathrm{~d}$. CVF treatment, when given in the period immediately before and after grafting, delayed but did not prevent the cellular immune response induced by the graft, demonstrating that xenografted neural tissue can activate the humoral arm of the rejection process, in particular the complement cascade. This suggests that interventions targeting this aspect of the immune rejection process may be of great importance for the future development of xenotransplantation for neurodegenerative conditions.

Key words: porcine xenograft; complement; rejection; Parkinson's disease; mesencephalic; rat

zoonotic infection (for review, see Weiss, 1999), as well as its rejection, even in the relatively immunologically privileged site of the CNS (Isacson and Breakefield, 1997; Larsson et al., 1999). Indeed, these issues currently represent the two major obstacles to the widespread adoption of this tissue in a clinical program of neural transplantation.

Vascularized whole organ xenografts (e.g., pig to primate) when placed in the periphery are rejected within minutes by a hyperacute antibody-directed complement-mediated process (Auchincloss and Sachs, 1998). In contrast, cell suspension xenografts placed in the periphery (e.g., porcine pancreatic islet cells) evoke a combination of $\mathrm{T}$ - and B-cell-mediated processes that result in the grafts being lost over the course of days to weeks (Marchietti et al., 1996; Mirenda et al., 1997; Oberholzer et al., 1999). In the case of neural xenografts placed in the CNS, a T-cell response has been documented that in the majority of cases leads to rejection of the tissue over the ensuing 3-4 weeks (for review, see Sloan et al., 1991; Pakzaban and Isacson, 1994). This rejection can be abrogated, although not always abolished, by the use of cyclosporin A (CyA) as well as other more broadly targeted immunosuppressive regimes (Finsen et al., 1988; Brundin et al., 1989; Honey et al., 1990; Pedersen et al., 1995; Wood et al., 1996). This suggests that the rejection process may not be solely a T-cell-mediated phenomena, and indirect evidence for this comes from earlier studies (Brundin et al., 1989; Finsen et al., 1990; Duan et al., 1995) as well as more recent in vitro and grafting studies using immunoglobulin knockout mice (Deacon et al., 1998; Larsson et al., 1999; Sumitran et al., 1999).

We therefore undertook a series of studies to explicitly address the relative role of humoral and cellular rejection processes with neural porcine xenografts placed in the adult mammalian CNS. 


\section{MATERIALS AND METHODS}

All experiments were conducted under the regulatory control of the UK Animals (Scientific Procedures) Act, 1986 and associated codes of conduct.

\section{Animals}

Fifty-four, 8, and 20 female Sprague Dawley rats (Interfauna, Huntingdon, UK) weighing 180-200 gm at the start of the experiment were used in experiments 1,2 , and 3, respectively. The animals were housed in groups of six rats per cage under natural light/dark cycle and with free access to food and water.

\section{Lesions}

Animals in experiments 1 and 3 received a unilateral 6-hydroxydopamine (6-OHDA) lesion of the right nigrostriatal bundle performed under halothane anesthesia, as described previously (Barker et al., 1995). Briefly, $8 \mu \mathrm{g} / 2 \mu \mathrm{l}$ 6-OHDA $\mathrm{HBr}$ in $0.1 \%$ ascorbate/saline was injected stereotactically under halothane anesthesia into the right nigrostriatal bundle at coordinates anterior to bregma (A) $-4.4 \mathrm{~mm}$, lateral to bregma (L) $-0.9 \mathrm{~mm}$, and vertical below dura (V) $-7.8 \mathrm{~mm}$ with the nose bar set $2.3 \mathrm{~mm}$ below the interaural line. Injections were delivered over $4 \mathrm{~min}$ with a 30 gauge stainless steel cannulae, and an additional 2 min was allowed for diffusion before the needle was withdrawn and the wound sutured.

\section{Drug-induced rotation}

Two weeks after receiving the 6-OHDA lesion, the rats were tested in automated rotometer bowls modeled after Ungerstedt and Arbuthnott (1970). Met-amphetamine sulfate (Sigma, St. Louis, MO; 2.5 $\mathrm{mg} \cdot \mathrm{kg}^{-1} \cdot \mathrm{ml}^{-1} 0.9 \%$ saline) was injected intraperitoneally, and rotation was monitored over a period of $90 \mathrm{~min}$. This was repeated twice for all animals. All animals with rotational scores of greater than five turns per minute under met-amphetamine were regarded as having good lesions and were allocated to the control or experimental group in a counterbalanced order.

Grafted rats were retested at 10,21 , and $35 \mathrm{~d}$ after implantation.

\section{Preparation of the embryonic ventral mesencephalic grafts}

The preparation of the porcine ventral mesencephalic (VM) tissue was similar to that described for in vitro studies (Barker et al., 1999). Briefly, the VM was dissected from a single litter of E25 porcine tissue [crownrump length $(\mathrm{CRL})=16.5 \mathrm{~mm}]$ under sterile conditions in $0.1 \mathrm{M} \mathrm{PBS}, \mathrm{pH}$ 7.4 , with $0.6 \%$ glucose and pooled. The tissue was placed into a $1.5 \mathrm{ml}$ Eppendorf and incubated in $0.05 \%$ bovine trypsin (Worthington/Cooper, Cambridge BioScience) for $15-20 \mathrm{~min}$ at $37^{\circ} \mathrm{C}$. DNase $(0.001 \%)$ (Sigma) was added, and the whole preparation was spun at $100 \times g$ for 2 min. After centrifugation, the supernatant was removed, and $1 \mathrm{ml}$ of a 50:50 mix of triturating solution [containing $1 \mathrm{mg}$ bovine serum albumin (BSA), $10 \mathrm{mg}$ DNase, and $0.5 \mathrm{mg}$ soybean trypsin inhibitor (Sigma) per $\mathrm{ml}$ PBS] and culture medium [containing 80\% DMEM (Imperial Lab), $20 \%$ fetal calf serum (Flow), and penicillin, streptomycin, and fungizone (Sigma)] was added. The tissue was triturated with 10-15 passages through a flame-polished Pasteur pipette, and a viability count was performed using trypan blue. The whole preparation was then recentrifuged to give a final volume of $1 \mathrm{VM} / 4 \mu \mathrm{l}$ of suspension, with a cell density of 200,000 cells per microliter and a viability of $99 \%$ in experiment 1 . In experiment 2, one embryonic day 28 (E28) litter was used with a cell density of 500,000 cells per microliter and a viability of $91 \%$. In experiment 3, three E25 litters were used with a cell density of 500,000 cells per microliter and a viability of 99,97 , and $88 \%$, respectively, for the three separate suspensions that were grafted.

The preparation of the rat ventral mesencephalic tissue for control isografting in experiment 1 was similar to that described previously (Barker et al., 1995) and used a single E14 litter (CRL $12 \mathrm{~mm}$ ) of the same Sprague Dawley strain as the recipients. In summary, the VM was dissected free from the rest of the CNS and meninges and prepared in identical fashion to the porcine tissue, with a density 77,000 cells per microliter and a viability of $91 \%$.

\section{Graft implantation}

Experiment 1. Twenty rats received E25 porcine VM xenografts, 16 rats received E14 rat VM isografts, and 6 rats had 6-OHDA lesions only. An additional 12 animals, without any 6-OHDA lesions, received sham grafts of $2 \mu \mathrm{l}$ of HBSS. Eight of the isografted animals also received sham grafts of HBSS in the contralateral non-dopamine deafferented striatum (see Fig. 1).

Under halothane anesthesia, each 6-OHDA-lesioned animal received a stereotaxic injection of the suspension as a single $2 \mu \mathrm{l}$ deposit into the dopamine deafferented striatum at coordinates A $+0.6 \mathrm{~mm}, \mathrm{~L}-2.4 \mathrm{~mm}$, and $\mathrm{V}-4.5 \mathrm{~mm}$ with the incisor bar set $2.3 \mathrm{~mm}$ below the interaural line. The sham-grafted animals received an identical volume of HBSS into the right striatum at these same coordinates, with the isografted animals receiving sham grafts of HBSS at the same coordinates, except that it was placed at $\mathrm{L}+2.4 \mathrm{~mm}$. Each deposit was made with a 23 gauge needle at the rate of $1 \mu \mathrm{l} / \mathrm{min}$, with a $3 \mathrm{~min}$ diff usion time at the end of the graft placement with the needle left in the grafted site.

Experiment 2. The level of antibody response to porcine embryonic neural tissue and blood was ascertained in a separate experiment. Rats received either intrastriatal grafts of pig lymphocytes or embryonic E28 VM tissue ( $n=4$ per group), and these were performed as detailed in experiment 1.

The pig lymphocytes were separated using a standard procedure. In essence, $10 \mathrm{ml}$ of blood was diluted with an equal volume of HBSS at room temperature, then layered onto an equal volume of Ficoll (Histopaque 1077; Sigma) using a $10 \mathrm{ml}$ plastic pipette, and centrifuged at $2600 \mathrm{rpm}$ at room temperature for $30 \mathrm{~min}$ with no brake. The mononuclear cells from the interface were then placed into a $50 \mathrm{ml}$ centrifuge tube that was then diluted with $50 \mathrm{ml}$ of cold HBSS and centrifuged at $2200 \mathrm{rpm}$ at $4^{\circ} \mathrm{C}$ for $15 \mathrm{~min}$ with the brake on. The pellet was resuspended in $1 \mathrm{ml}$ cold HBSS and then made up to $30 \mathrm{ml}$ with more cold HBSS and centrifuged at $2000 \mathrm{rpm}$ for $10 \mathrm{~min}$ at $4^{\circ} \mathrm{C}$. The final cell suspension was made up to a density of 500,000 cells $/ 2 \mu \mathrm{l}$ with a viability of $79 \%$.

Experiment 3. Twenty rats received intrastriatal grafts of E25 porcine VM tissue as described for experiment 1 . Half of these animals then received cobra venom factor as detailed below.

\section{Systemic antibody responses}

To assess the extent to which the neural xenograft induced a systemic antibody response, serum was obtained from all animals before implantation of either porcine neural tissue or lymphocytes and at 5 and $10 \mathrm{~d}$ after implantation. The serum was obtained by tail-bleeding the rat and collecting no more than $1 \mathrm{ml}$ of blood, which was then allowed to clot and was centrifuged at 14,000 rpm for $15 \mathrm{~min}$. The serum was then withdrawn and stored immediately at $-70^{\circ} \mathrm{C}$.

The serum from the rats was then tested for an antibody response using both measurements of anti-pig hemolytic antibodies and total $\operatorname{IgM} \kappa$ concentrations in the sera.

Measurement of anti-pig hemolytic antibodies. Complement fixation test diluent (CFD) tablets (Oxoid) were made up by dissolving one tablet in $100 \mathrm{ml}$ of distilled water. Fresh pig blood $(2 \mathrm{ml}$, collected in lithiumheparin Sarstedt monovette tubes) was then placed in a universal container and made up to $20 \mathrm{ml}$ with CFD and spun at $750 \times g$ for $6 \mathrm{~min}$ at $4^{\circ} \mathrm{C}$. The supernatant was discarded, and the washing procedure was repeated twice. One milliliter of the washed pig blood cells (PRBCs) was added to an Eppendorf tube and spun in a microcentrifuge at $17,000 \times$ $\mathrm{g}$ for $2 \mathrm{~min}$, after which the supernatant was removed and $100 \mu \mathrm{l}$ PRBCs was added to $9.9 \mathrm{ml}$ CFD to make a 1:100 solution.

Aliquots $(45 \mu \mathrm{l})$ of the sera samples [including normal rat sera control (NRS); Sigma] were heat-inactivated $\left(30 \mathrm{~min}\right.$ at $56^{\circ} \mathrm{C}$ ), and the sera were diluted with $180 \mu \mathrm{l} \mathrm{CFD}$ to make a 1:5 stock. CFD $(50 \mu \mathrm{l})$ was added to wells in columns $2-10$ of a 96 -well, rigid v-bottom plate (Sterilin 612V96) with all serum samples being run in duplicate, along rows. Fifty microliters of the sera from the 1:5 stock solution were added to wells in column 1 and 2, and the sera was serially diluted from columns $2-10$, with the last $50 \mu \mathrm{l}$ being discarded. CFD $(50 \mu \mathrm{l})$ was added to two wells for

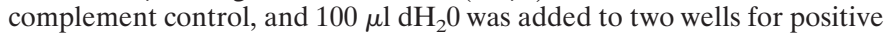
control. PRBC $(50 \mu \mathrm{l})$ was then added to all wells, followed by $50 \mu \mathrm{l}$ baby rabbit complement, with the exception of the positive controls [(Serotec) which was made up by reconstitution with $1 \mathrm{ml}$ distilled water to which was then added $9 \mathrm{ml} \mathrm{CFD} \mathrm{for} \mathrm{a} \mathrm{1:90} \mathrm{dilution].} \mathrm{Plates} \mathrm{were} \mathrm{incubated} \mathrm{for}$ $1 \mathrm{hr}$ in an orbital incubator at $37^{\circ} \mathrm{C}$ after which it was spun at $500 \times \mathrm{g}$ for $10 \mathrm{~min}$ at $4^{\circ} \mathrm{C}$. Supernatant $(100 \mu \mathrm{l})$ was then transferred to a 96-well, flat-bottom flexible plate (Falcon 3912) and read at $420 \mathrm{~nm}$ on Dynex plate reader.

The mean and SD of the data were calculated, and the mean optical densities were plotted with the area under the curve being calculated and standardized to NRS equaling 1000.

Method for measuring IgMк in rat sera. Flat-bottomed, 96-well flexible 
plates (Falcon 3912) were coated with $10 \mu \mathrm{g} / \mathrm{ml}$ mouse anti-rat IgM (Clone MARM-4; Biosource, Camarillo, CA) in bicarbonate/carbonate coating buffer and incubated at $4^{\circ} \mathrm{C}$ overnight. The plate was then washed three times with $0.1 \%$ Tween/PBS and blocked with $200 \mu \mathrm{l}$ per well of $5 \%$ skimmed milk (Marvel) in $\mathrm{PBS}$ at $37^{\circ} \mathrm{C}$ for $2 \mathrm{hr}$. The plate was then washed with $0.1 \%$ Tween/PBS, and the rat sera samples and standards were added at $100 \mu \mathrm{l}$ per well and run in duplicate. Rat IgM $\kappa$ standards (Serotec) were run at 2500, 625, 156.3, 39.1, 9.8, 2.4, 0.6, and $0 \mathrm{ng} / \mathrm{ml}$ with normal rat sera samples run at two dilutions, 1:25,000 and 1:50,000, and rat test samples run at $1: 25,000$. The plates were incubated at $37^{\circ} \mathrm{C}$ for 2 $\mathrm{hr}$ and washed three times with $0.1 \%$ Tween/PBS. One hundred microliters per well of mouse anti-rat $\kappa$-chain HRP (Clone MARK-1; Biosource) at $500 \mathrm{ng} / \mathrm{ml}$ was added and incubated at $37^{\circ} \mathrm{C}$ for $2 \mathrm{hr}$ and then washed three times with $0.1 \%$ Tween/PBS; $200 \mu \mathrm{l}$ per well of Sigma fast (Sigma) was added, and plates were incubated at room temperature for $30 \mathrm{~min}$ in the dark. Plates were read at $450 \mathrm{~nm}$ using Dynex plate reader, and concentrations were automatically calculated from the standard curve.

\section{Decomplementation}

Decomplementation was achieved using CVF because it is known to activate complement and leads to its consumption and thus depletion (Vogel, 1992). To evaluate the efficacy of CVF in depleting complement activity in the Sprague Dawley rat, four control rats without lesions or grafts were treated with CVF (Imutran Limited, Cambridge, UK) over a $12 \mathrm{~d}$ period. The rats were venesected through their tails before and 1 , $5,6,7,8,9$, and $11 \mathrm{~d}$ into this regimen of $\mathrm{CVF}$ administration, and complement hemolytic activity was assayed in serum samples (CH50 assay) using sheep erythrocytes sensitized with monoclonal anti-sheep IgM antibody (Harrison and Lachman, 1986).

In experiment 3 , rats receiving $\mathrm{CVF}$ were divided into two groups. One group received no CVF, whereas the other received a $500 \mu \mathrm{g} / \mathrm{kg}$ intraperitoneal injection of CVF $24 \mathrm{hr}$ before grafting and thereafter at a dose of $250 \mu \mathrm{g} / \mathrm{kg}$ on days $1,3,5$, and 7 after implantation (given that complement activity returns to normal despite continued CVF administration) (see Results and Fig. 5).

In the graft study, all rats were tail-bled just before CVF administration and/or grafting and 5 and $10 \mathrm{~d}$ after implantation. The serum was analyzed for $\mathrm{CH} 50$ activity as well as for circulating antibody levels (see above).

\section{Histochemistry}

At the end of the experiment the animals were killed by a lethal injection of sodium pentobarbitone (Sagatal, May and Baker) and perfused through the left ventricle with $150 \mathrm{ml}$ prewash (0.1 M PBS, pH 7.4) followed by $600 \mathrm{ml}$ of $4 \%$ paraformaldehyde in PBS. The brains were then post-fixed for $4 \mathrm{hr}$ in $4 \%$ paraformaldehyde and transferred to $25 \%$ sucrose made up in PBS until they sank. Sections were then cut on a sledge microtome (usually $60 \mu \mathrm{m}$ ) from the anterior margin of the corpus callosum to the pons, and six parallel series were collected in $0.1 \mathrm{M}$ Tris-buffered saline, $\mathrm{pH}$ 7.4. One series was mounted onto glass slides and stained with cresyl violet; other series were stained for TH (polyclonal, 1:4000; Jacques Boy), pig-specific neurofilament (monoclonal, 1:500; Dr. Luis Soriano, Paris, France), CD8 + cells (monoclonal, 1:500; Serotec), Complement C3 (monoclonal, 1:500; Serotec), ED-1 (monoclonal, 1:500;), and rat-specific IgM (monoclonal, 1:200; Serotec) using standardized protocols and biotinylated goat anti-rabbit or rat adsorbed biotinylated goat anti-mouse Ig (Dako, Glostrup, Denmark) (Barker et al., 1995).

\section{Graft volume and cell numbers}

Cell counts were made of TH-positive cells in the grafts in experiment 1 , and total numbers were estimated using the Abercrombie correction factor. The volume of the graft was also calculated for both cresyl violet histochemistry and pig neurofilament immunostaining using an image analysis package and scaling for section thickness and sampling frequency (1:6) in experiments 1 and 3 (Seescan, Cambridge, UK).

\section{Cellular infiltrate}

The extent of the CD8 and ED1 cellular infiltrate in experiment 3 was done blinded by an independent investigator using a scoring system in which the extent of the infiltrate was $0=$ none, $1=$ sparse numbers of cells present, 2 = significant cellular infiltrate, and $3=$ florid cellular infiltrate. IgM immunoreactivity in and around the graft was graded

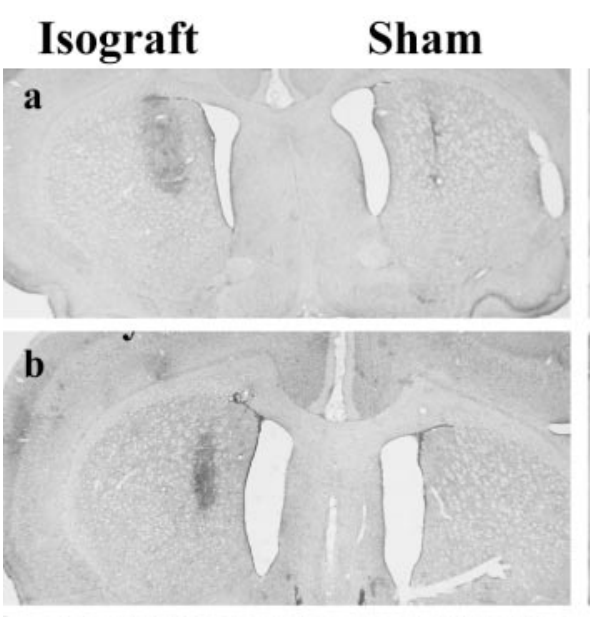

\section{Xenograft}
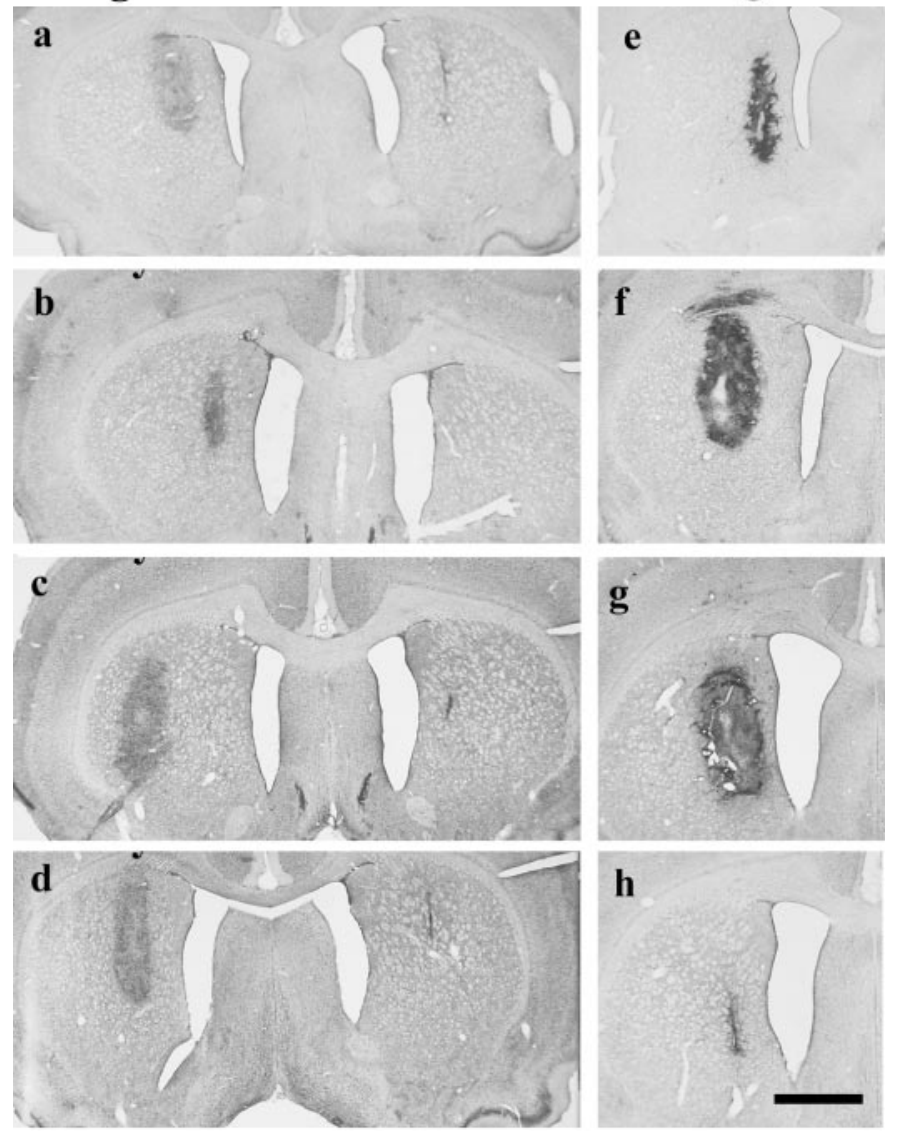

Figure 1. Cresyl violet of sham, isografts, and xenografts. $a$, Five-day-old isograft with a sham graft in the contralateral striatum that is seen as a small scar-like structure. $b-d$, Over the ensuing $30 \mathrm{~d}$, the isograft increases slightly in volume but with no increase in cellularity. $b$, Ten-day-old isograft; $c, 21$-d-old isograft with sham graft in contralateral striatum; $d$, 35 -d-old isograft with sham graft in contralateral striatum; $e, 5$-d-old xenograft with hypercellularity already apparent in graft; $f$, 10-d-old xenograft in which the graft has expanded in size and increased cellularity is maintained. $g$, At $21 \mathrm{~d}$ there is necrosis within the graft, and by $35 \mathrm{~d}(h)$ the graft has been lost and a small gliotic scar is left. Scale bar, $1 \mathrm{~mm}$.

using a similar scoring system in which $0=$ no immunoreactivity and $3=$ florid throughout the graft.

\section{Data analysis}

Data were analyzed by ANOVA, using the Genstat 5.3 statistical package (AFRC, Rothamstead, UK), with Newman-Keuls test for post hoc comparisons. The Mann-Whitney $t$ test was used for the nonparametric analysis of CD8 and ED1 immunoreactivity scores, because of considerable heterogeneity of variance of these conditions.

\section{RESULTS}

\section{Experiment 1: the immunohistochemical characterization of the rejection profile of porcine VM xenografts}

\section{Graft size and morphology}

The sham control animals received no tissue grafts, but the needle track was seen in these animals (Fig. 1). Isografted animals all had surviving grafts, which were $\sim 1 \mathrm{~mm}^{3}$ in volume and did not change significantly in volume over time (Figs. 1,a-d, 2) $\left(F_{3,11}\right.$ $=1.70 ; \mathrm{NS})$. In contrast, although all xenografted animals had identifiable grafts, their volumes changed dramatically over time 

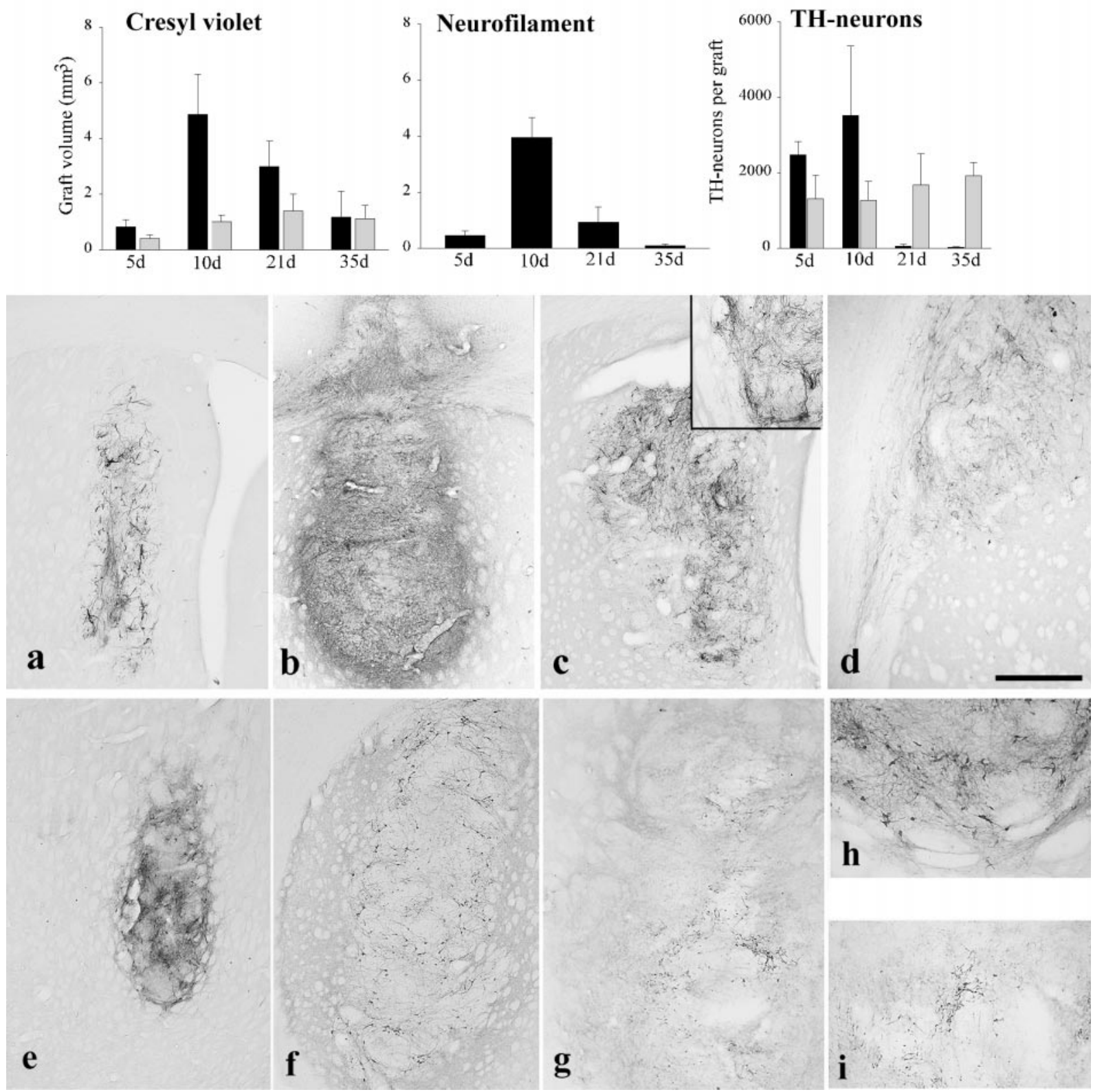

Figure 2. Volume of isografts and xenografts with time. Cresyl violet: Isografts increase slightly in volume over the first 3 weeks and thereafter remain stable. In contrast, xenografts show a dramatic increase in volume that then declines as the grafts are lost such that at $35 \mathrm{~d}$ they are of comparable size to allografts, although they show much greater variability (mean \pm SEM). Neurofilament: Xenograft volumes using pig-specific neurofilament staining show a pattern similar to that seen with cresyl violet, implying that the increase in graft volume is not simply the consequence of an inflammatory infiltrate (mean \pm SEM). TH-neurons: The number of TH-positive neurons in isografts remains constant over time, whereas xenografts have variable numbers of TH-positive neurons at the early time points that disappear as the graft is lost to the rejection process (mean \pm SEM). Black columns represent xenografts; light gray columns represent isografts. $a-d$, Pig-specific neurofilament staining of the xenografts. $a$, A 5-d-old xenograft with neurofilament staining within it that $(b)$ increases and becomes more intense at $10 \mathrm{~d}$. $c$, It is still present at $21 \mathrm{~d}$ after implantation, but there is no significant penetration of the fibers into the host striatum (inset). However, neurofilament-positive fibers emerging from the graft can follow white matter tracts such as the corpus callosum $(d)$. By $35 \mathrm{~d}$ there is no neurofilament staining because the graft is lost (data not shown). $e-i$, TH immunohistochemistry of isografts and xenografts. Intense TH staining within isografts is seen at $(e) 10 \mathrm{~d}$ and $(f) 21 \mathrm{~d}$ after implantation. By this final time point the typical peripheral distribution of TH cell bodies is seen with fiber outgrowth into the host striatum $(h) . g$, In contrast, 10-d-old xenografts show less intense staining with only a few TH cell bodies being identified (i). Scale bar (shown in $d$ ): $a-c, 250 \mu \mathrm{m} ; d, 100 \mu \mathrm{m} ; e-g, 0.5 \mathrm{~mm} ; h, i, 200 \mu \mathrm{m}$.

(Fig. 2, Cresyl violet) $\left(F_{3,15}=5.08 ; p<0.05\right)$. At $5 \mathrm{~d}$ after transplantation the grafts were small and "pencil-like" (Fig. 1e), but by $10 \mathrm{~d}$ they had increased in size (Fig. $1 f$ ). At $21 \mathrm{~d}$, cavitation within the graft was apparent (Fig. $1 g$ ). Thereafter the grafts got smaller as they were rejected (Fig. $1 h$ ).

The increase in size of the graft was not simply a consequence of the inflammatory infiltrate, because pig-specific neurofilament staining shows fibers throughout the expanded graft mass (Fig. $2 a-d)$. Furthermore, the measurement of graft volume with this marker gave statistically significant differences between time points, similar to that seen with the basic histological stain (Fig. 2, Neurofilament $)\left(F_{3,13}=23.96 ; p<0.001\right)$. At later time points, the 
graft volumes are smaller using neurofilament staining as opposed to cresyl violet as the graft is rejected.

TH-positive neurons were found in all isografts, and the number of such cells remained constant throughout the time course of the study (Fig. 2, TH-neurons) $\left(F_{3,12}=0.38\right.$; NS). The mean number of TH-positive cells overall for the isografted animals was $1510 \pm 284$ cells. These cells at all time points showed intense TH staining with fiber outgrowth into the host striatum (Fig. $2 e-i)$. In contrast, the number of TH-positive cells varied over time in the xenografted animals, although this change did not reach statistical significance because of the large variability between animals at any one time $\left(F_{3,15}=2.67\right.$; NS). At $5 \mathrm{~d}$, a large number of TH-positive cells were identified, although they demonstrated faint staining with limited fiber outgrowth. By $10 \mathrm{~d}$, the number of TH cells within the grafts had increased, although they varied greatly from animal to animal, ranging from 402 to 12,480 , depending on the degree to which the graft was being rejected. The cells stained faintly for $\mathrm{TH}$ and had only limited fiber outgrowth that was entirely confined to the graft (Fig. $2 g, i)$, with no observable outgrowth of fibers into the host brain. In contrast, pig-specific neurofilament staining at these time points demonstrated fiber outgrowth from the graft that was most noticeable along the corpus callosum where fibers extended several millimeters (Fig. $2 d$ ), although fiber outgrowth from the graft into the host striatum was not seen (Fig. 2c). At 20 and 35 d, no TH cells were seen in xenografts even when the grafts stained positively for neurofilament (Fig. 2c), suggesting that TH expression was lost before the final rejection of the graft.

\section{Cellular immune response to the graft}

Sham grafts elicited a small nonspecific CD8-positive cell response at $5 \mathrm{~d}$, but subsequently no lymphocytes were seen at the implantation site. Isografts similarly induced little cellular response at any time point, with only sparse CD8-positive cells seen at all time points (Fig. 3e), which was not particularly perivascular in its distribution.

Xenografts, on the other hand, induced a marked CD8-positive cellular response that was present at all time points. This response probably represented predominantly T-lymphocytes, although rat natural killer cells and macrophages could not be excluded given that they can express CD8. At 5 after grafting, the xenografts contained limited numbers of $\mathrm{CD} 8+$ cells, which were perivascular in their distribution and streaming into the graft (Fig. 3a). This infiltrate increased over the next 2 weeks such that the grafts were heavily infiltrated by these cells at both 10 and $21 \mathrm{~d}$ after implantation (Fig. $3 b, c$ ). By $35 \mathrm{~d}$ after implantation, the number of $\mathrm{CD} 8+$ cells had decreased as the grafts were undergoing the last stages of rejection and forming a scar (Fig. 3d).

\section{Complement and IgM binding within and around the graft}

Neither sham nor isografts induced any specific IgM or complement response from the host at any time points (Fig. $3 j, o$ ). By contrast, $5 \mathrm{~d}$ after transplantation of the xenograft, there was IgM and $\mathrm{C} 3$ binding in or around the grafts (Fig. $3 f, k$ ), which increased such that by $10 \mathrm{~d}$, florid IgM and C3 staining had developed both around and within the grafts (Fig. $3 g, l$ ). This binding was specifically on elements within the graft (Fig. 3h, inset). By 21 and 35 d, complement staining remained largely within and immediately around the grafts, whereas the IgM response had became more diff use (Fig. 3h,i,m,n).

\section{Rotational behavior}

Xenografted animals did not show a significant reduction in amphetamine-induced rotation compared with control, in contrast to isografted animals (Fig. 4) (groups $\times$ time interaction; $\left.F_{6,57}=8.55 ; p<0.001\right)$. In the isografted animals, a reduction in rotation from the pretransplantation baseline was already apparent at the first test, $10 \mathrm{~d}$ after implantation. Thereafter there was a further reduction, with apparent overcompensation in some animals by day 35 . Sham injected animals did not receive 6-OHDA lesions and so were not subjected to drug-induced rotation.

\section{Experiment 2: the systemic antibody response to porcine VM xenografts}

Peripheral grafting of pig lymphocytes or embryonic pig VM tissue is known to induce a systemic antibody response (A. Richards, unpublished data). In contrast, intracerebral injections of porcine lymphocytes or VM tissue produced no measurable rise in either the total levels of $\mathrm{IgM} \kappa$ or the degree of lysis of porcine red blood cells up to $10 \mathrm{~d}$ after implantation (data not shown).

\section{Experiment 3: the effects of complement depletion on the rejection profile of porcine VM xenografts}

Systemic cobra venom factor treatment and complement depletion

The systemic administration of CVF fully depleted the rat of complement activity for only $7 \mathrm{~d}$ (Fig. 5). Thereafter the level of complement activity increased and returned to pre-CVF levels, although CVF continued to be injected every other day throughout this period. Thus grafted animals received CVF treatment from -1 to day 7 after implantation, and the CH50 assay confirmed that these animals had depleted complement activity $5 \mathrm{~d}$ after grafting (data not shown).

\section{Cellular infiltrate}

The cellular infiltrate was assessed semiquantitatively using a predominant lymphocyte marker (CD8) and a macrophage/microglia marker (ED1) (see Materials and Methods). CD8-positive cells were seen in the majority of grafts, and although overall there was no significant difference caused by the relatively small numbers of animals (day $\times$ treatment interaction $F_{1,16}=2.87$; NS), a trend was apparent at the earlier time point. At $10 \mathrm{~d}$ after implantation, there was a difference in the CD8 infiltrate that reached significance using a more restricted nonparametric analysis (Fig. 6; $U_{9}=2.00, p<0.05$ ). Those animals receiving CVF had a greatly reduced CD8 cell infiltrate, especially when compared with those receiving no CVF (Fig. 6a,e), an effect that had disappeared by $21 \mathrm{~d}$ (Fig. $6 b, f ; U_{9}=11.50, \mathrm{NS}$ ).

The number of ED1-positive cells showed a pattern similar to the CD8 infiltrate, although the magnitude of the effect was less (Fig. $6 c, d, g, h ; F_{1,16}=2.12$, NS). However, the ED1 response was more intense in all animals at both 10 and $21 \mathrm{~d}$ compared with that seen for the CD8 infiltrate (Fig. 6).

\section{Immunoglobulin/complement response}

The grafts induced an IgM response that tended to be slightly less in the CVF-treated animals compared with those that received none at earlier time points, but did not reach statistical significance (Fig. 6) $\left(F_{1,16}=1.09\right.$; NS). The difference in IgM deposition was much less than that seen with the cellular markers. 

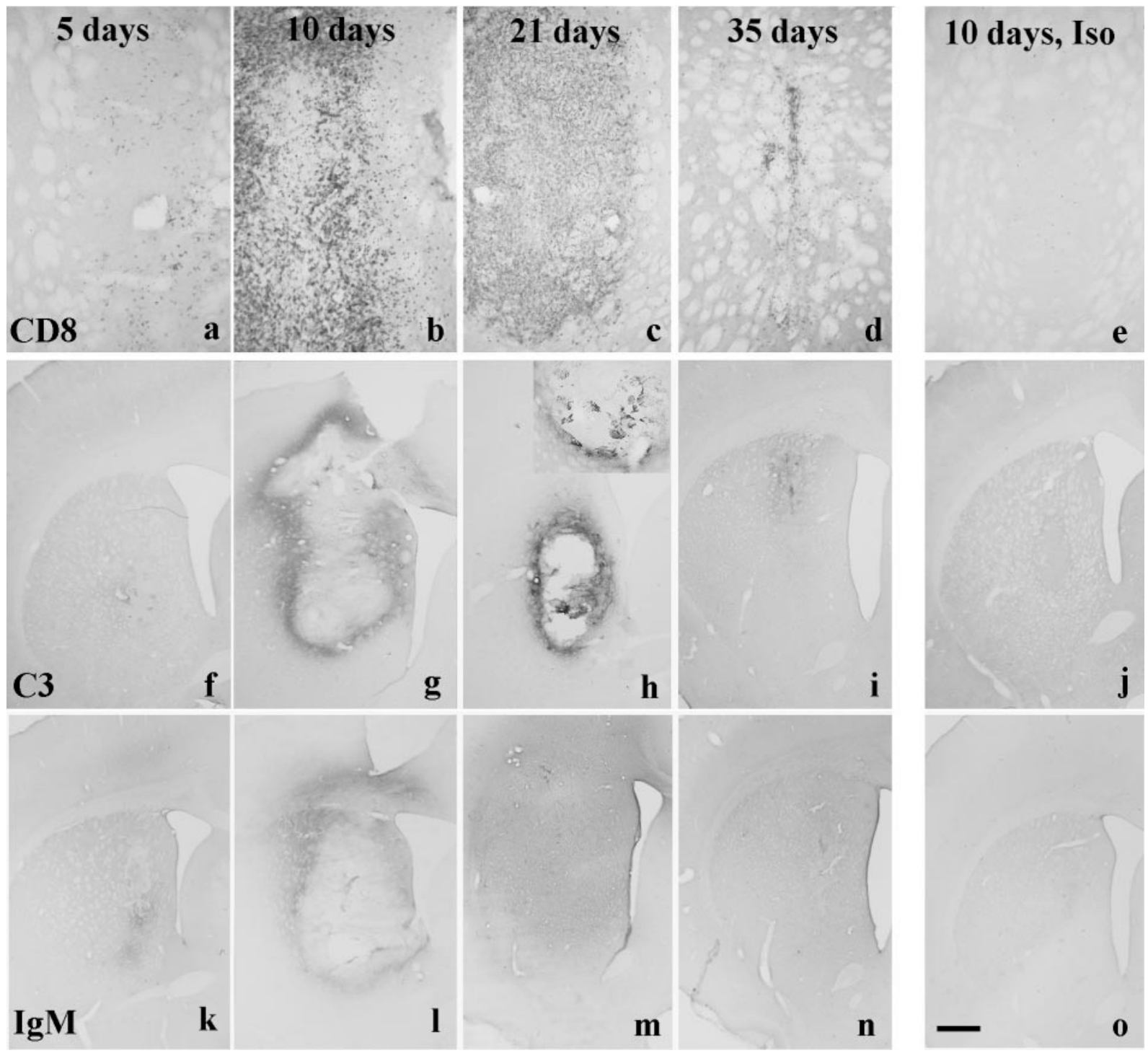

Figure 3. $a-e$, CD8 staining in xenografts and isografts. $a$, Five-day-old xenografts contain a few CD8+ cells and by $(b) 10 \mathrm{~d}$ the staining is intense and extends outside the borders of the graft. $c$, It is still present at $21 \mathrm{~d}$ after implantation, although it wanes as the graft is lost such that $(d)$ by $35 \mathrm{~d}$ only a few CD8 + cells are seen scattered around the site of the original graft. $e$, In contrast, a 10-d-old isograft has no CD8+ cells within it. $f-j$, Complement (C3) staining in isografts and xenografts. $f$, There is minimal complement staining in the xenograft at $5 \mathrm{~d}$ after implantation. In contrast $(g)$ there is clear staining in and around the graft at $10 \mathrm{~d}$ that $(h)$ persists at day 21 and is more clearly seen at higher power (inset). $i$, By day 35 the staining has become less intense as the graft is rejected. $j$, In contrast, 10 -d-old isografts have no such complement binding. $k-o$, Rat-specific IgM staining in isografts and xenografts. $k$, There is some IgM staining in the xenograft at $5 \mathrm{~d}$ after implantation. $l$, By $10 \mathrm{~d}$ it has become more apparent and is around and within the graft. $m$, At $21 \mathrm{~d}$ the staining is diff use and involves the whole hemisphere, $(n)$ a pattern of staining that is also seen at $35 \mathrm{~d} . o$, In contrast, a 10 -d-old isograft induces no such IgM binding. Scale bar (shown in $o$ ): $a-e, 0.5 \mathrm{~mm} ; f-o, 1 \mathrm{~mm}$.

C3 staining showed an absence of staining at $10 \mathrm{~d}$ in all animals receiving $\mathrm{CVF}$, but by $21 \mathrm{~d}$ they all exhibited $\mathrm{C} 3$ staining within the graft as had been shown in experiment 1 (not shown).

\section{Graft volume}

The volume of the grafted tissue was assessed using a routine histological stain (Fig. 7a, Cresyl Violet) and pig-specific neurofilament to assess the neuronal component of the graft as for experiment 1 (Fig. $7 b$ ). In addition, an index of the approximate inflammatory infiltrate was obtained by subtracting the graft volume using neurofilament from that obtained using cresyl violet (Fig. 7c). Cresyl violet will stain all the cells within the graft mass, whereas the neurofilament will only label the pig neurons and this latter volume will therefore always be less than that obtained using cresyl violet. The difference between this two measures of graft volume gives an approximate measure of the inflammatory infiltrate, assuming that animals in both groups (i.e., CVF and non-CVF treated) contain the same numbers of glial cells, which would be a reasonable assumption given the common source of tissue for grafting.

The graft volumes varied according to the administration of the CVF, although the differences did not reach statistical significance using either cresyl violet or pig-specific neurofilament to define volume (treatment $\times$ time interaction; cresyl violet $F_{1,16}=$ 0.56 , neurofilament $F_{1,16}=0.48$,cellular infiltrate $F_{1,16}=2.87$; all NS). The early administration of $\mathrm{CVF}$ tended to reduce the 


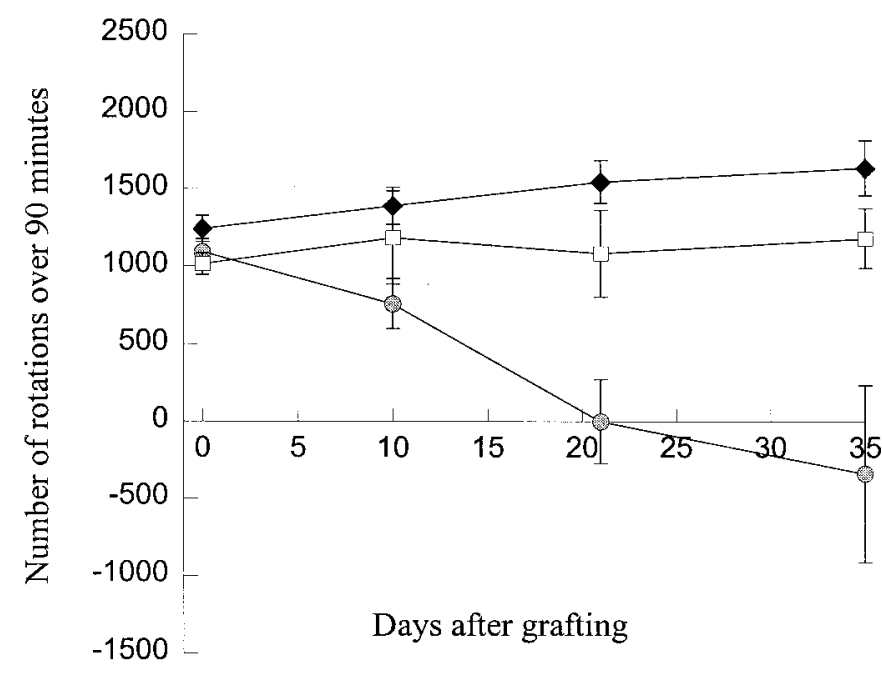

Figure 4. Met-amphetamine-induced rotation in isografted, xenografted, and lesion only animals before and after transplantation showing a significant reduction in rotation in isografted animals only (mean \pm SEM). Sham-grafted animals did not receive 6-OHDA lesions so were not subjected to drug-induced rotation. White squares, Lesion only; gray circle, isografted animals; black square, xenografted animals.

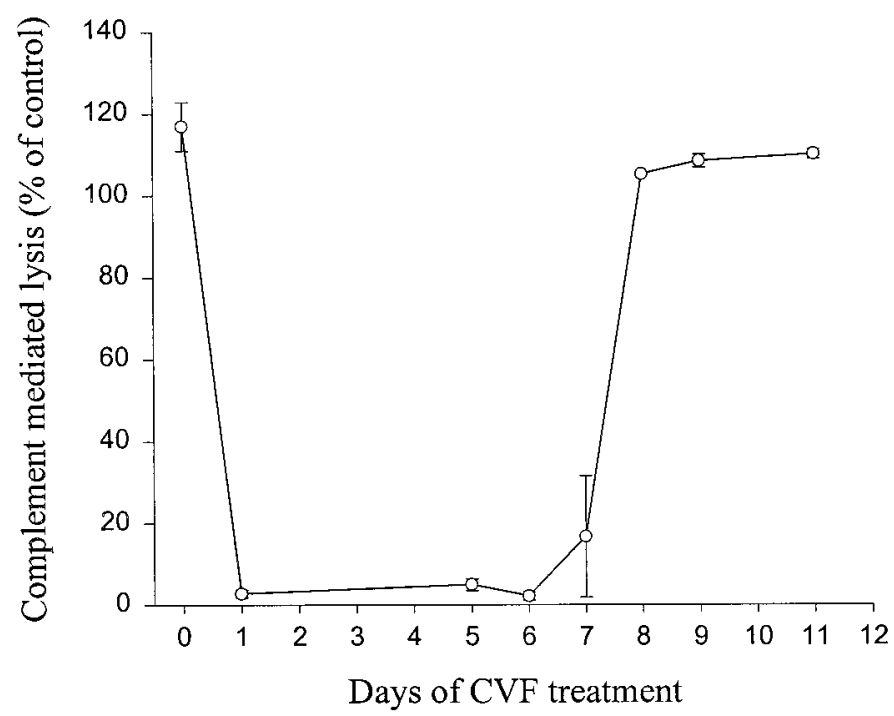

Figure 5. Complement depletion with cobra venom factor treatment at a dose of $500 \mu \mathrm{g} / \mathrm{kg}$ intraperitoneally at day 0 and thereafter at a dose of $250 \mu \mathrm{g} / \mathrm{kg}$ on days $2,4,6,8,10$, and 12 . Complement hemolytic activity was measured through lysis of sheep erythrocytes sensitized with IgM antibody and represented relative to a control value of $100 \%$ (mean \pm SEM).

overall volume of the graft at $10 \mathrm{~d}$, whereas the volume of neurofilament-positive tissue remained constant across grafted groups. This suggests that there may be smaller grafts with early CVF administration and that this may represent a reduction in the extent of the inflammatory infiltrate, which is supported by a more detailed analysis of the cellular infiltrate (see above).

At $21 \mathrm{~d}$ the animals with grafts and no CVF had largely been rejected, although the extent to which this had been completed was variable, as was seen in experiment 1 . The CVF-treated animals now had graft volumes comparable to that seen in the nontreated group, although the extent of the "cellular infiltrate" was greater in the CVF-treated animals, implying that there may be a delay in the rejection process.

All grafts had few TH-positive cells within them, and most of these were poorly visualized as a consequence of the rejection process. Therefore, no accurate quantification of the number of TH-positive cells within the grafts was possible in this experiment.

\section{Drug-induced rotation}

All animals had a significant rotational response to $2.5 \mathrm{mg} / \mathrm{kg}$ met-amphetamine after unilateral 6-OHDA of the right nigrostriatal bundle. However, none of the xenografted animals showed a significant reduction in rotation over the $21 \mathrm{~d}$ of the study $\left(F_{2,28}=5.06, \mathrm{NS}\right)$.

\section{DISCUSSION}

This study has shown that porcine VM xenotransplants are rejected in the nonimmunosuppressed 6-OHDA rat model of PD over a $35 \mathrm{~d}$ period and that this rejection process involves complement activation. The earliest immunological changes were already present at $5 \mathrm{~d}$ after implantation and consisted of a CD8 cellular infiltrate, which by $10 \mathrm{~d}$ had increased in intensity and was associated with $\operatorname{IgM}$ and complement deposition within and around the graft. The combined humoral and CD8 response then paralleled graft rejection over the subsequent 2-3 weeks. Systemic CVF treatment was used to achieve a limited period of complement depletion and altered the temporal pattern of the cellular neural xenograft rejection process, although it did not prevent it. The evidence for this comes not only from specific immunostains for subsets of inflammatory cells but also from the overall reduction in the total volume of the graft in the absence of any change in the neurofilament component within it. We have also shown that the rejection of porcine neural xenografts does not produce a measurable systemic antibody response, despite IgM binding within the graft. This may be because the change is too small to be detected by the assays that we used, or alternatively there is a delay in the antibody response such that it is not apparent at $10 \mathrm{~d}$ after grafting. Certainly embryonic porcine neural tissue, as well as porcine lymphocytes, can provoke a measurable systemic antibody response when placed peripherally into the peritoneal cavity of rats (A. Richards, unpublished data).

Previous studies on the rejection of neural xenografts have concentrated on the cellular aspect of the process and shown that in the immediate period after implantation there is a nonspecific polymorphonuclear lymphocytic infiltrate that disappears within $5 \mathrm{~d}$ and is replaced by a T-cell infiltrate that is present until the graft is lost (Mason et al., 1986; Kohsaka et al., 1989; Finsen et al., 1990; Pollack et al., 1990; Duan et al., 1995). This T-cell infiltrate coincides with increased major histocompatability (MHC) class II antigen expression and the activation of microglia and reaches a peak at $\sim 14 \mathrm{~d}$, after which the response wanes as the graft is lost. The process can be modified by various immunosuppressive regimes (Brundin et al., 1985; Inoue et al., 1985; Finsen et al., 1988, 1990; Brundin et al., 1989; Sakei et al., 1991; Zhou et al., 1993; Pakzaban et al., 1995; Duan et al., 1996; Okura et al., 1997a,b), although in all cases some grafts are still lost unless the animal is immature at the time of implantation (Marion et al., 1990). The reason for the immunosuppressive therapy failing to prevent rejection in some cases is not known, but a central role for the T-lymphocyte seems likely, given that the use of specific antibodies to CD4-positive lymphocytes or the IL-2 receptor has proven more successful (Honey et al., 1990; Wood et al., 1996). 

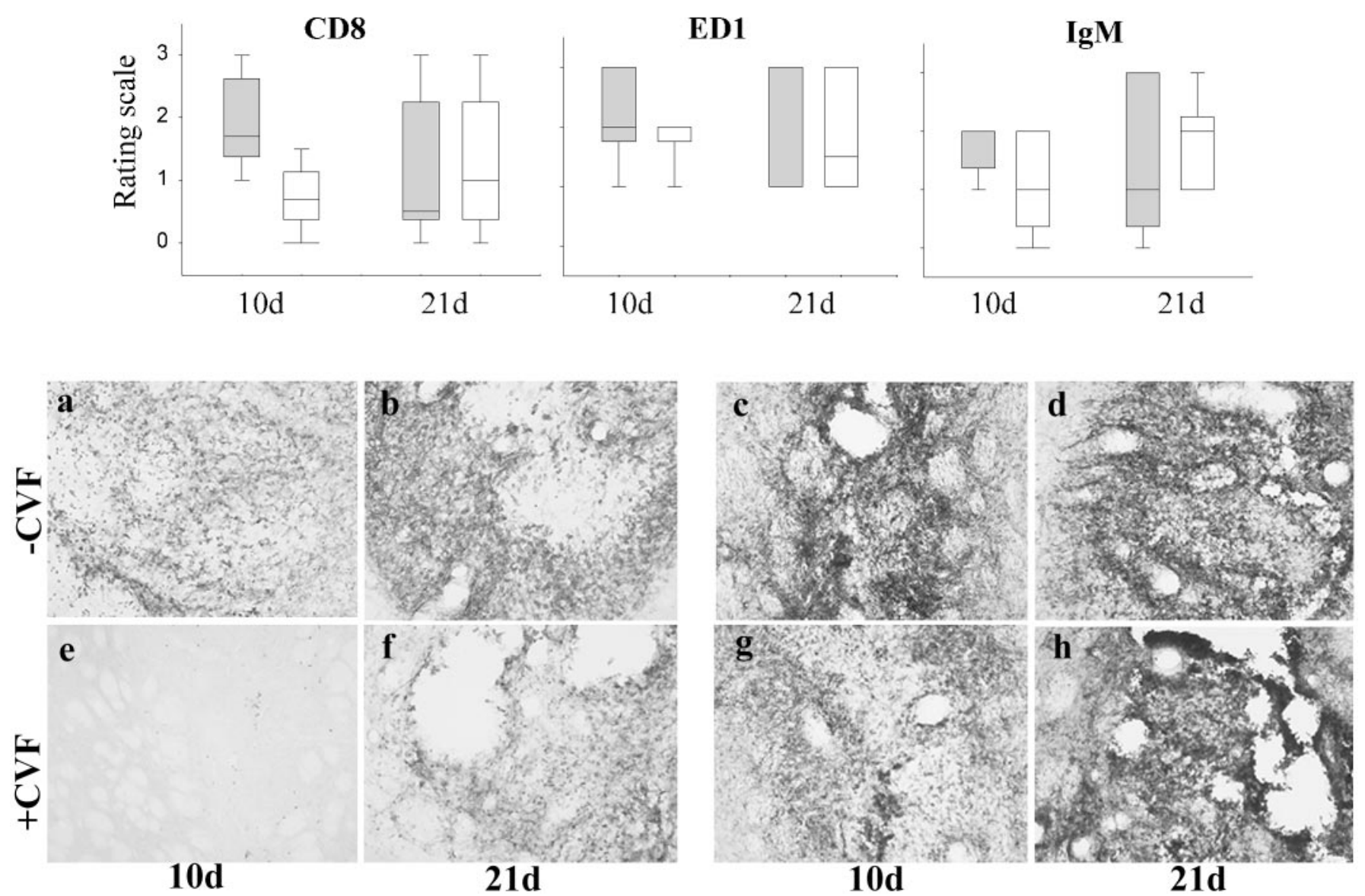

Figure 6. The relative infiltration of CD8-positive cells, ED1-positive macrophages/microglia, and IgM binding at days 10 and 21 after implantation in animals receiving CVF compared with those that received none. There is a significant lack of CD8-positive cells at $10 \mathrm{~d}$ in those animals treated with $\mathrm{CVF}$, and although ED1-positive cells showed a similar pattern, this did not reach statistical significance. By $21 \mathrm{~d}$ there was no difference between those animals receiving and not receiving CVF. With respect to IgM, although there is a slight tendency for less IgM binding in those animals receiving CVF, this was a marginal effect and less than that seen for the cellular infiltration and microglia/macrophage activation response. The boxed plot represents the median value and $75 \%$ confidence limits, with the bars representing $95 \%$ confidence limits for the data. Gray, No CVF; white, CVF. $a-h$, CD8 and ED1 staining of xenografts with and without CVF treatment. $a$, Ten-day-old xenografts contain a dense CD8 infiltrate that is also $(b)$ seen at day 21 after implantation. $c$, ED1 staining of 10-d-old xenografts shows a marked microglia reaction and/or macrophage infiltration in the graft, which (d) persists and is still clearly visible at day 21 after implantation. $e$, In contrast, animals receiving CVF have a greatly reduced CD8 infiltrate at $10 \mathrm{~d}$ after grafting, although $(f)$ by day 21 the infiltrate is similar to that seen in the control, no CVF-treated animals. $g$, CVF-treated animals also had a less marked ED1 response at $10 \mathrm{~d}$ after grafting, although the reduction is less than that seen for CD8 staining. $h$, By day 21 the response is more marked and similar to that seen in the control, no CVF-treated animals.

A role for non-T-cell-mediated processes in the rejection of xenografts is also probable, and we have now directly demonstrated this for the first time. The first indirect evidence for this came from Brundin et al. (1989), who commented that some of their rats grafted with mouse VM tissue into the striatum developed antibodies to donor tissue MHC antigens, although the presence and titer of that antibody response did not correlate with graft survival. Finsen et al. (1990) came to a similar conclusion with solid mouse hippocampal grafts placed in the adult rat. Duan et al. (1995), however, using mouse to rat VM grafts, postulated that the neural xenograft may be subject to an acute, noncellular antibody complement-mediated process, although no evidence for this was presented. However, none of these studies used porcine to rat xenografts, which represents a greater immunological incompatibility than mouse to rat xenografts. In this respect, Deacon et al. (1998) have recently shown that grafts of neural tissue derived from transgenic pigs expressing the human CD59 cell surface complement inhibitor survive in the CyA-immunosuppressed rat.

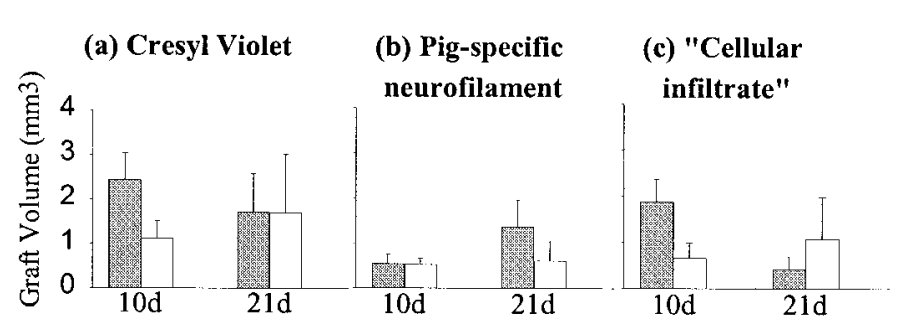

Figure 7. $a-c$, The volume of xenografts in animals treated with CVF compared with those that received no such treatment using $(a)$ cresyl violet staining to delineate graft extent, $(b)$ pig-specific neurofilament (NF70) staining to delineate the neuronal component of the graft, and (c) the cellular infiltrate that is derived from subtracting the neurofilament graft volume from that obtained using cresyl violet histochemistry. This gives a nonspecific measure of the non-neuronal aspect of the graft that comprises glial cells and an inflammatory infiltrate, and given that both groups of animals should have grafts with similar glial profiles, the major difference is in the degree to which the grafts have attracted an inflammatory cellular infiltrate. Gray columns, No CVF; white columns, CVF. 
Furthermore, fresh embryonic porcine neural tissue can be lysed in a complement-dependent fashion by both primate and human sera (Deacon et al., 1998; Sumitran et al., 1999), although the antigen to which the antibody binds is not solely Gal- $\alpha 1,3-$ Gal (Sumitran et al., 1999), the major epitope responsible for the hyperacute rejection of peripheral vascularized whole organ xenografts. Indeed a role for humoral processes in the rejection of neural xenografts in situ has now been demonstrated with Ig knockout (IgKO) mice by Larsson et al. (1999). In their study, porcine neural xenografts placed in the IgKO mice survive for longer periods than grafts placed in the normal, wild-type mouse (Larsson et al., 1999).

Our study, although supporting earlier studies on the T-cell response to xenografted neural tissue, specifically demonstrates for the first time that the cellular infiltration is accompanied by a humoral response and that inhibiting complement reduces the cellular rejection response, similar to that reported for porcine islet cell xenografts. CVF that leads to the consumption of complement and thus its depletion (Vogel, 1992) was given as repeated doses in our rats and led to a substantial reduction in complement activity for $7 \mathrm{~d}$, after which repeated administration failed to produced any further reduction. The gradual restoration of normal complement levels despite repeated CVF administration probably results from the development of antibodies to CVF. As a result, only a limited period of complement depletion could be guaranteed. Previously, this approach has been undertaken with pig to rat xenografts of islet cells and has shown that even short-term treatment with CVF can delay the rejection of these grafts (Oberholzer et al., 1999) by reducing the CD4- and CD8positive cellular infiltrate within the graft. These cells may represent macrophages as opposed to lymphocytes (Wallgren et al., 1995), which in turn may be mediating rejection through complement or antibody binding to the surface of the grafted cells. Indeed, rat to mouse islet cell grafts have been shown to have IgM and C3 deposition on the grafted cells, a situation not seen with allografts of this tissue (Deng et al., 1994). In our study, CVF treatment reduced the cellular infiltrate into the grafts, and the CD8-positive cells were especially affected by this process. In addition, the number of ED1-positive cells [a marker for rat macrophages/microglia (see for example Oudega et al., 1999)] tended also to be less in this group compared with those not receiving $\mathrm{CVF}$. Other leukocyte markers were looked for but failed to stain for technical reasons. In contrast, the deposition of IgM within the grafts was not significantly different in the CVFtreated animals compared with controls.

The mechanism by which complement contributes to neural xenograft rejection is unresolved by this study, as is the site of its synthesis. It is possible that the complement is generated locally in response to the xenograft, because all components of the complement cascade are known to exist in the rat brain and to be activated by a number of stimuli (Morgan and Gasque, 1996). In this respect the graft may be inducing local, rather than systemic, complement activation; whatever, the effects of decomplementation in neural xenograft rejection may be mediated through a nonspecific effect on the acute inflammatory response, or alternatively it may be acting in a more specific fashion by modulating specific antigen-driven immune responses (Erdei et al., 1991). In vitro complement has been shown to influence the presentation of antigen to B- and T-cells (Arvieux et al., 1988) as well as the T-cell proliferative response to IL-2 (Erdei et al., 1984). It is therefore possible that in this paradigm complement is important in triggering leukocyte infiltration (Pratt et al., 1996) and may even be important in enhancing the immunogenicity of the xenograft (Dempsey et al., 1996).

This study has important implications in the development of a clinical program using neural xenografts (Barker et al., 2000). Previously, neural xenografts were thought to have been lost to a T-cell-dependent process, and thus CyA, which acts on T-cell activation, should be an effective immunosuppressant. However, the survival rate with CyA monotherapy and neural xenografts is only $\sim 60-70 \%$ (Pakzaban and Isacson, 1994), although it can be improved when CyA is coadministered with other immunosuppressive drugs such as azathioprine and steroids (Pedersen et al., 1995). This implies that more broadly targeted immunotherapy may be more effective, a view that this paper corroborates by demonstrating a clear role for complement in the rejection process. This perspective is further supported in the clinical domain by the failure of CyA monotherapy to provide significant graft survival in a patient with PD receiving a porcine VM xenograft (Deacon et al., 1997). Indeed, the successful development of transgenic tissue with regulators of the human complement system to ameliorate the hyperacute rejection of vascularized whole organ transplants (Fodor et al., 1994; Rosengard et al., 1995) may also be advantageous for neural xenografts.

In summary, therefore, we have demonstrated that porcine VM grafts placed into the 6-OHDA-lesioned rat do not survive in the nonimmunosuppressed recipient and this rejection process involves complement activation. However, although the presence of a complement-mediated process has now been demonstrated, the relationship of this to other aspects of the rejection process, especially the T-cell response, awaits clarification.

\section{REFERENCES}

Auchincloss H, Sachs DH (1998) Xenogeneic transplantation. Annu Rev Immunol 16:433-470.

Arvieux J, Yssel H, Colomb MG (1988) Antigen-bound C3b and C4b enhance antigen-presenting cell function in activation of human T-cell clones. Immunology 65:229-235.

Barker RA, Fricker RA, Abrous DN, Fawcett J, Dunnett SB (1995) A comparative study of preparation techniques for improving the viability of nigral grafts using vital stains, in vitro cultures, and in vivo grafts. Cell Transplant 4:173-200.

Barker RA, Ratcliffe E, Richards A, Dunnett SB (1999) Fetal porcine dopaminergic cell survival in vitro and its relationship to embryonic age. Cell Transplant 8:593-599.

Barker RA, Kendall AL, Widner H, and the "Neural Tissue Xenografting Project" (2000) Neural tissue xenotransplantation: what is needed prior to clinical trials? Cell Transplant, in press.

Brundin P, Nilsson OG, Gage FH, Björklund A (1985) Cyclosporin A increases survival of cross-species intrastriatal grafts of embryonic dopamine-containing neurons. Exp Brain Res 60:204-208.

Brundin P, Widner H, Nilsson OG, Strecker RE, Björklund A (1989) Intracerebral xenografts of dopamine neurons: the role of immunosuppression and the blood-brain barrier. Exp Brain Res 75:195-207.

Deacon T, Schumacher J, Dinsmore J, Thomas C, Palmer P, Kott S, Edge A, Penney D, Kassissieh S, Dempsey P, Isacson O (1997) Histological evidence of fetal pig neural cell survival after transplantation into a patient with Parkinson's disease. Nat Med 3:350-353.

Deacon TW, Fodor W, Rollins S, Squinto S, Constantini LC, Matis L, Bell L, Isacson O (1998) Xenotransplantation of transgenic fetal pig dopamine neurons to rats and systemic prevention of host complementmediated cell lysis. Soc Neurosci Abstr 421.9:1056.

Dempsey PW, Allison ME, Akkaraju S, Goodnow CC, Fearon DT (1996) C3d of complement as a molecular adjuvant: bridging innate and acquired immunity. Science 271:348-350.

Deng S, Buhler L, Lou J, Grau G, Redard M, Bubloz C, Rohner A, Morel $P$ (1994) Study of concordant xenografted islets of Langerhans rejection: humoral or cellular mechanism? Transplant Proc 26:1184-1185.

Duan W-M, Widner H, Brundin P (1995) Temporal pattern of host responses against intrastriatal grafts of syngeneic, allogeneic or xenogeneic embryonic neuronal tissue in rats. Exp Brain Res 104:227-242. 
Duan WM, Brundin P, Grasbon-Frodl EM, Widner H (1996) Methylprednisolone prevents rejection of intrastriatal grafts of xenogeneic embryonic neural tissue in adult rats. Brain Res 712:199-212.

Erdei A, Spaeth E, Alsenz J, Rude E, Schulz T, Gergely J, Dierich MP (1984) Role of C3b receptors in the enhancement of interleukin-2dependent T-cell proliferation. Mol Immunol 21:1215-1221.

Erdei A, Fust G, Gergely J (1991) The role of C3 in the immune response. Immunol Today 12:332-337.

Fahn S, Greene PE, Tsai W-Y, Eidelberg DE, Winfield H, Dillon S, Kao R, Winfield L, Breeze RE, Freed CR (1999) Double-blind controlled trial of human embryonic dopaminergic tissue transplants in advanced Parkinson's disease: clinical outcomes. Neurology 52[Suppl 2]: A405.

Finsen B, Poulsen PH, Zimmer J (1988) Xenografting of fetal mouse hippocampal tissue to the brain of adult rats: effects of Cyclosporin A treatment. Exp Brain Res 70:117-133.

Finsen BR, Pedersen EB, Sørensen T, Hokland M, Zimmer J (1990) Immune reactions against intracerebral murine xenografts of fetal hippocampal tissue and cultured cortical astrocytes in the adult rat. Prog Brain Res 82:111-128.

Fodor WL, Williams BL, Matis LA, Madri JA, Rollins SA, Knight JW, Velander W, Squinto SP (1994) Expression of a functional human complement inhibitor in a transgenic pig as a model for the prevention of xenogeneic hyperacute organ rejection. Proc Natl Acad Sci USA 91:11153-11157.

Harrison RA, Lachman PJ (1986) Complement technology. In: Handbook of experimental immunology, Vol 1 (Weir DM, ed), p 19. Oxford: Blackwell Science.

Honey CR, Clarke DJ, Dallman MJ, Charlton HM (1990) Human neural graft function in rats treated with anti-interleukin II receptor antibody. NeuroReport 1:247-249.

Inoue H, Kohsaka S, Yoshida K, Ohtani M, Toya S, Tsukada Y (1985) Cyclosporin A enhances the survivability of mouse cerebral cortex grafted into the third ventricle of rat brain. Neurosci Lett 54:85-90.

Isacson O, Breakefield XO (1997) Benefits and risks of hosting animal cells in the human brain. Nat Med 3:964-969.

Kohsaka S, Shinozaki T, Nakano Y, Takei K, Toya S, Tsukada Y (1989) Expression of Ia antigen on vascular endothelial cells in mouse cerebral tissue grafted into third ventricle of rat brain. Brain Res 484:340-347.

Kopyov OV, Jacques S, Lieberman A, Duma CM, Eagle KS (1998) Safety of intrastriatal neurotransplantation for Huntington's disease patients. Exp Neurol 149:97-108.

Kordower JH, Freeman TB, Olanow CW (1998) Neuropathology of fetal nigral grafts in patients with Parkinson's disease. Mov Disord 13:88-95.

Larsson LC, Czech KA, Widner H, Korsgren O (1999) The role of immunoglobulins in the rejection of discordant neural xenografts. Transplantation 27:1153-1160.

Lindvall O (1997) Neural transplantation: a hope for patients with Parkinson's disease. NeuroReport 8:iii-x.

Marion DW, Pollack IF, Lund RD (1990) Patterns of immune rejection of mouse neocortex transplanted into neonatal rat brain, and effects of host immunosuppression. Brain Res 519:133-143.

Marchietti P, Scharp DW, Finke EH, Swanson CJ, Olack BJ, GerasimidiVazeou D, Giannarelli R, Navalesi R, Lacy PE (1996) Prolonged survival of discordant porcine islet xenografts. Transplantation 61:1100-1102.

Martin WRW, Perlmutter JS (1994) Assessment of fetal tissue transplantation in Parkinson's disease: does PET play a role? Neurology 44:1777-1780.

Mason DW, Charlton HM, Jones AJ, Lavy BD, Puklavec M, Simmonds SJ (1986) The fate of allogeneic and xenogeneic neuronal tissue transplanted into the third ventricle of rodents. Neuroscience 19:685-694.

Mirenda V, Sigalla J, Fiche M, Thibaudeau K, Huvelin JM, Soulillou JP, Le Mauff B (1997) Pig pancreatic islet xenografts in a B-cell deficient mouse model. Transplant Proc 29:762-763.

Morgan BP, Gasque P (1996) Expression of complement in the brain: role in health and disease. Immunol Today 17:461-466.

Oberholzer J, Yu D, Triponez F, Cretin N, Andereggen E, Mentha G, White D, Buehler L, Morel P, Lou J (1999) Decomplementation with cobra venom factor prolongs survival of xenografted islets in a rat to mouse model. Immunology 97:173-180.
Okura Y, Tanaka R, Ono K, Yoshida S, Tanuma N, Matsumoto Y (1997a) Treatment of rat hemiparkinson model with xenogeneic neural transplantation: tolerance induction with anti-T-cell antibodies. J Neurosci Res 48:385-396.

Okura Y, Tanaka R, Ono K, Yoshida S, Tanuma N, Matsumoto Y (1997b) Immunohistochemical analysis on the rejection of xenogeneic brain grafts. Restor Neurol Neurosci 11:177-187.

Oudega M, Vargas CG, Weber AB, Kleitman N, Bunge MB (1999) Long-term effects of methylprednisolone following transection of adult rat spinal cord. Eur J Neurosci 11:2453-2464.

Pakzaban P, Isacson O (1994) Neural xenotransplantation: reconstruction of neuronal circuitry across species barriers. Neuroscience 62:989-1001.

Pakzaban P, Deacon TW, Burns LH, Dinsmore J, Isacson O (1995) A novel mode of immunoprotection of neural xenotransplants: masking of donor major histocompatability complex I enhances transplant survival in the central nervous system. Neuroscience 65:983-996.

Pedersen EB, Poulsen FR, Zimmer J, Finsen B (1995) Prevention of mouse-rat brain xenograft rejection by a combination of cyclosporin A, prednisolone and azathioprine. Exp Brain Res 106:181-186.

Pollack IF, Lund RD, Rao K (1990) MHC antigen expression in spontaneous and induced rejection of neural xenografts. Prog Brain Res 82:129-140.

Pratt JR, Hibbs MJ, Laver AJ, Smith RA, Sacks SH (1996) Allograft immune response with sCR1 intervention. Transpl Immunol 4:72-75.

Rosengard AM, Cary NR, Langford GA, Tucker AW, Wallwork J, White DJ (1995) Tissue expression of human complement inhibitor, decayaccelerating factor, in transgenic pigs. A potential approach for preventing xenograft rejection. Transplantation 59:1325-1333.

Sakei K, Date I, Yoshimoto Y, Arisawa T, Nakashima H, Furuta T, Asari S, Ohmoto T (1991) The effect of a new immunosuppressive agent, FK-506, on xenogeneic neural transplantation in rodents. Brain Res 565:167-170.

Sloan DJ, Wood MJ, Charlton HM (1991) The immune response to intracerebral neural grafts. Trends Neurosci 14:341-346.

Sumitran S, Liu J, Czech KA, Christenson B, Widner H, Holgersson J (1999) Human natural antibodies cytotoxic to pig embryonic brain cells recognize novel non Gal- $\alpha 1,3-\mathrm{Gal}$ based xenoantigens. Exp Neurol 159:347-361.

Ungerstedt U, Arbuthnott GW (1970) Quantitative recording of rotational behavior in rats after 6-hydroxydopamine lesions of the nigrostriatal dopamine system. Brain Res 24:485-493.

Vogel C (1992) Cobra venom factor. In: Encylopaedia of immunology (Roitt I, Delves P, eds), p 363. London: Academic.

Wallgren AC, Karlsson-Parra A, Korsgren O (1995) The main infiltrating cell in xenograft rejection is a $\mathrm{CD} 4{ }^{+}$macrophage and not a $\mathrm{T}$ lymphocyte. Transplantation 60:594-601.

Weiss RA (1999) Xenografts and retroviruses. Science 285:1221-1222.

Wenning GK, Odin P, Morrish P, Rehncrona S, Widner H, Brundin P, Rothwell J, Brown R, Gustavii B, Hagell P, Jahanshahi M, Sawle G, Björklund A, Brooks D, Marsden CD, Quinn NP, Lindvall O (1997) Short- and long-term survival and function of unilateral intrastriatal dopaminergic grafts in Parkinson's disease. Ann Neurol 42:95-107.

Wictorin K, Brundin P, Sauer H, Lindvall O, Björklund A (1992) Long distance directed axonal growth from human dopaminergic mesencephalic neuroblasts implanted along the nigrostriatal pathway in 6-hydroxydopamine lesioned adult rats. J Comp Neurol 22:475-494.

Widner H (1998) The Lund transplant program for Parkinson's disease and patients with MPTP-induced parkinsonism. In: Cell transplantation for neurological disorders: toward reconstruction of the human central nervous system (Freeman TB, Widner H, eds), pp 1-17. Totowa, NJ: Humana.

Wood MJA, Sloan DJ, Wood KJ, Charlton HM (1996) Indefinite survival of neural xenografts induced with anti-CD4 monoclonal antibodies. Neuroscience 70:775-789.

Zhou J, Date I, Sakai K, Furuta T, Asari S, Ohmoto T (1993) Suppression of immunorejection against rat fetal dopaminergic neurons in a mouse brain by 15-deoxyspergualin. Brain Res. 621:155-160. 